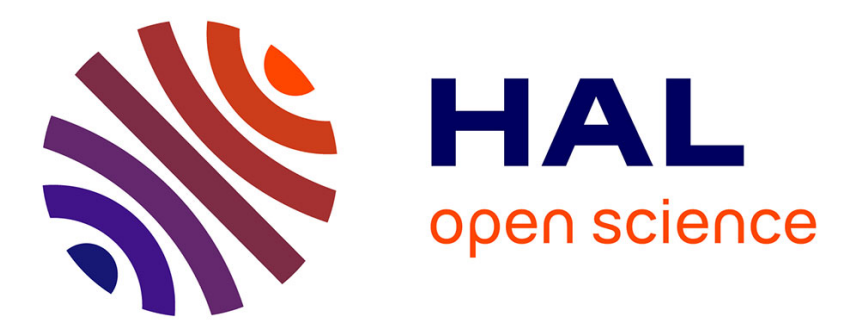

\title{
Thermoelectric properties, metal-insulator transition, and magnetism: Revisiting the Ni1-xCuxS2 system
}

Antoine Maignan, Ramzy Daou, Emmanuel Guilmeau, David Berthebaud, Tristan Barbier, Oleg Lebedev, Sylvie Hebert

\section{To cite this version:}

Antoine Maignan, Ramzy Daou, Emmanuel Guilmeau, David Berthebaud, Tristan Barbier, et al.. Thermoelectric properties, metal-insulator transition, and magnetism: Revisiting the Ni1-xCuxS2 system. Physical Review Materials, 2019, 3, pp.115401. 10.1103/PhysRevMaterials.3.115401 . hal03039678

\section{HAL Id: hal-03039678 https://hal.science/hal-03039678}

Submitted on 4 Dec 2020

HAL is a multi-disciplinary open access archive for the deposit and dissemination of scientific research documents, whether they are published or not. The documents may come from teaching and research institutions in France or abroad, or from public or private research centers.
L'archive ouverte pluridisciplinaire HAL, est destinée au dépôt et à la diffusion de documents scientifiques de niveau recherche, publiés ou non, émanant des établissements d'enseignement et de recherche français ou étrangers, des laboratoires publics ou privés. 


\title{
Thermoelectric properties, metal-insulator transition and magnetism: revisiting the $\mathrm{Ni}_{1-\mathrm{x}} \mathrm{Cu}_{\mathrm{x}} \mathrm{S}_{2}$ system
}

Antoine Maignan, Ramzy Daou, Emmanuel Guilmeau, David Berthebaud, Tristan Barbier, Oleg Lebedev and Sylvie Hébert*

\section{Laboratoire CRISMAT, UMR 6508 CNRS, ENSICAEN, UNICAEN, Normandie Université, 6 bd du Maréchal Juin - 14050 Caen - France}

\begin{abstract}
The $\mathrm{Ni}_{1-x} \mathrm{Cu}_{x} \mathrm{~S}_{2}$ pyrite $(x \leq 0.07)$ is a model material where the impact of electron filling on a half-filled $e_{g}$ band system can be separated from changes in the bandwidth, since the unit cell volume does not change with $x$. This contrasts with the $\mathrm{NiS}_{2-x} \mathrm{Se}_{x}$ system where the size difference between $\mathrm{S}^{2-}$ and $\mathrm{Se}^{2-}$ makes the bandwidth vary at constant band filling. Our magnetic measurements show that there exists a clear relation between the presence of the antiferromagnetic phase developing below $T_{\mathrm{N} 2}=29.75 \mathrm{~K}$ and charge localization. With the addition of $\mathrm{Cu}$ in $\mathrm{Ni}_{1-x} \mathrm{Cu}_{x} \mathrm{~S}_{2}$, the ground state evolves towards a metallic paramagnetic state. These new findings are discussed with the scenario based on charge ordering at low temperature in the charge transfer insulator $\mathrm{NiS}_{2}$ pyrite, and also considering possible conducting surface states at low temperatures. At $300 \mathrm{~K}$, the thermal conductivity decreases by 2.5 as $x$ increases from 0.00 to 0.07 , even though the latter is much more electrically conductive than the former. This considerably extends the range of values for the thermal conductivity of the $\mathrm{MS}_{2}$ pyrites, from the largest in $\mathrm{FeS}_{2}$ to the lowest in the present $\mathrm{Ni}_{1-x} \mathrm{Cu}_{x} \mathrm{~S}_{2}$ samples.

* Corresponding author: sylvie.hebert@ensicaen.fr
\end{abstract}




\section{1-Introduction}

$\mathrm{NiS}_{2}$ crystallizes in the pyrite structure like other di-chalcogenides such as $\mathrm{CoS}_{2}$ and $\mathrm{FeS}_{2}$ [1]. The description of its electronic structure has evolved with time. $\mathrm{NiS}_{2}$ was first described as a prototypical example of a Mott-Hubbard insulator [2-7]. More recently, theory and experimental (photoemission) studies $[8,9]$ pointed towards a charge-transfer insulator with a band gap between the $\mathrm{S}$ anion $3 p$ band at the highest valence states and Ni $3 d$ states at the bottom of the conduction band. Taking into account this peculiarity, the ground state is predicted to be insulating [8], in contrast to Density Functional Theory (DFT) calculations which indicate a metallic state [10]. The insulating state is actually very close to a metallic one with a large Fermi surface and heavy electrons, as revealed recently by transport data as a function of pressure where a metallic regime is recovered below $50 \mathrm{~K}$ above $3 \mathrm{GPa}$ [11]. In such a charge-transfer insulator scenario, the role of the $\left(\mathrm{S}_{2}\right)^{2-}$ dimers has to be considered as their bands lie across the band gap between occupied S- $p$ and unoccupied $\mathrm{Ni}-d$ states in a broad region of $d-p$ hybridization [8]. All these studies also demonstrated that both electronic and magnetic properties of $\mathrm{NiS}_{2}$ were strongly intertwined $[8,9,12,13]$.

The magnetic properties change a lot across the pyrite series: $\mathrm{CoS}_{2}$ is an itinerant ferromagnet with almost $1 \mu_{\mathrm{B}}$ per $\mathrm{Co}^{2+}$ (ref. [14] and references therein) for a $d^{7}$ band filling, whereas $\mathrm{NiS}_{2}$ is an insulating antiferromagnet with almost $1 \mu_{\text {в }}$ per $\mathrm{Ni}^{2+}\left(d^{8}\right)$ (ref. $\left.[13,15,16]\right)$. Moreover, $\mathrm{CuS}_{2}$, due to the $d^{9}$ electronic configuration of divalent $\mathrm{Cu}$, exhibits a metallic character and becomes a superconductor below $\mathrm{T}_{\mathrm{c}}=1.5 \mathrm{~K}$ [17].

Although most of the studies in line with the Mott-Hubbard scenario interpreted the effect of $\mathrm{Co}$ (or $\mathrm{Cu}$ ) for $\mathrm{Ni}$ substitution in $\mathrm{NiS}_{2}$ as a way to remove (or add) electrons in the half-filled e broad band [3-5], most recent 
ones pointed towards a possible charge disproportionation as the mechanism responsible for the insulating state [15]. The $\mathrm{NiS}_{2}$ magnetic behaviour is complex, with two different commensurate antiferromagnetic (AF) states, $\mathrm{M} 1$, below $\mathrm{T}_{\mathrm{N} 1}=39.2 \mathrm{~K}$, and $\mathrm{M} 2$, below $\mathrm{T}_{\mathrm{N} 2}=29.75 \mathrm{~K}$ [15]. The existence of a weak ferromagnetic component, which sets in below $T_{\mathrm{N} 2}$ and is thus associated to M2, can be observed by magnetic susceptibility measurements. Its origin has long been debated since the pyrite cubic $\mathrm{Pa} \overline{3}$ symmetry does not allow such a component. The coexistence of 4 different AF domains below $T_{\mathrm{N} 1}$ could explain it, if one of these magnetic structures is slightly changed [15] (for instance by a stoichiometry deviation). Interestingly, as the Se for S substitution suppresses concomitantly the M2 phase and the insulating state, the presence of the weak ferromagnetic component related to M2 is taken as a signature of the insulating state [15]. Apart from this charge ordering scenario, the low $\mathrm{T}$ transport properties have to be discussed with caution, as reports on $\mathrm{NiS}_{2}[18]$ and $\mathrm{FeS}_{2}[19,20]$ crystals of pyrite show that a surface layer with conducting states is responsible for apparent transitions in the $\mathrm{T}$ dependence of the electrical resistivity below $\sim 150 \mathrm{~K}$. These surface states can lead to lower resistivity values at $5 \mathrm{~K}$, compared to the charge ordered state.

Taking into account these different developments and the reports on an insulator to metal transition induced by only few at.\% $\mathrm{Cu}$ substitutions for $\mathrm{Ni}$ in $\mathrm{NiS}_{2}$ crystals [3] or ceramics [6], we have revisited the electronic, thermal and magnetic properties of the $\mathrm{Ni}_{1-x} \mathrm{Cu}_{x} \mathrm{~S}_{2}$ system with $\mathrm{x}$ varying up to 0.07 . Our results are consistent with the recent ones for $\mathrm{NiS}_{2-x} \mathrm{Se}_{x}$ [15]: with $\mathrm{x}$ increasing in $\mathrm{Ni}_{1-x} \mathrm{Cu}_{x} \mathrm{~S}_{2}$, the signature of the AF M2 state on the magnetic susceptibility curves is rapidly suppressed and from $x=0.05$, a metal-like ground state is obtained. The aim of this work is also to investigate a possible 
reduction of thermal conductivity in these pyrites by the substitution of Ni by $\mathrm{Cu}$. If an efficient reduction mechanism can be found in this family of materials, pyrites would be very interesting for thermoelectric applications as a very large power factor has already been measured in $\mathrm{CoS}_{2}[14]$.

In the following, we report on an experimental study of the effect of $\mathrm{Cu}$ substitution in $\mathrm{NiS}_{2}$ ceramic samples which shows a charge localization below about $T_{\mathrm{N} 2}$ at small x $(<0.05)$, replaced by a metallic state starting below about $100 \mathrm{~K}$ as soon as $x \geq 0.05$ in the $\mathrm{Ni}_{1-x} \mathrm{Cu}_{x} \mathrm{~S}_{2}$ series, and the electrical resistivity $(\rho)$ at $300 \mathrm{~K}$ which decreases by 2 orders of magnitude for only 2 at. $\% \mathrm{Cu}$ substitution. As already reported in ref. [3], the $\mathrm{Cu}$ substitution impacts the thermopower ( $S$, Seebeck coefficient), but it is also found that this substitution is efficient at reducing the total thermal conductivity $(\kappa)$, a bulk physical parameter, even though the electrical resistivity $(\rho)$ decreases, indicating that the lattice contribution to $\kappa$ is strongly reduced. These results are discussed in light of the surface effects reported for crystals of pyrites, which might bias the interpretation of the transport properties, and also of $\mathrm{Cu}$-induced melting of the charge ordered AF phase.

\section{2-Experimental}

The $\mathrm{Ni}_{1-x} \mathrm{Cu}_{x} \mathrm{~S}_{2}$ compounds, for $0 \leq x \leq 0.07$ and using $\Delta x$ step of 0.01 , were prepared by direct reaction of the pure elements $\mathrm{Ni}, \mathrm{Cu}$ and $\mathrm{S}$. In order to avoid air exposure, the following operations were all performed in an $\mathrm{Ar}$ glove-box. After weighting the latter ( $1 \mathrm{~g}$ in total) according to the $(1-x): x$ : 2 ratio, the powders were mixed, cold pressed in the form of bars and set in silica tubes that were sealed under primary vacuum. These closed vessels were 
heated at $973 \mathrm{~K}$ for $12 \mathrm{~h}$. For the three compositions $(x=0.00, x=0.01$ and $x$ $=0.07), 10 \mathrm{~g}$ were also reacted to provide the powder quantities needed for Spark Plasma Sintering (SPS). For these densification steps, after grinding, the powders were sintered at $1023 \mathrm{~K}$ for 30 minutes under $64 \mathrm{MPa}$ using graphite dies of $10 \mathrm{~mm}$ diameter. The geometrical densities were found to be greater than $90 \%$ of the crystallographic ones. The purity of the samples was checked by room temperature powder X-ray diffraction using an X'Pert Pro Panalytical diffractometer using $\mathrm{Cu} \mathrm{K}_{\alpha}$ radiation in a $2 \theta$ range of $10-120^{\circ}$. Characteristic diffraction peaks of $\mathrm{NiS}_{2}$ without additional ones were obtained (Figure 1), corresponding to a refined (LeBail refinements) unit cell parameter $a=5.688(1) \AA$ from $x=0.00$ to $a=5.684(1) \AA$ for $x=0.07$. Consistently with the similar ionic radii of $\mathrm{Cu}$ and $\mathrm{Ni}$ cations, no deviation of the unit cell parameter superior to $0.005 \AA$ was obtained showing a rather unchanged volume and thus a constant bandwidth. The copper content was checked by EDX coupled to electron diffraction in a $300 \mathrm{kV}$-Tecnai transmission electron microscope. Though the $\mathrm{Cu}$ contents were in the limit of the accuracy of the technique, these observations confirmed the homogeneous distribution of $\mathrm{Cu}$ in the matrix and the lack of $\mathrm{Cu}$ containing impurities. In the following, the compositions correspond to the nominal ones. The $\mathrm{NiS}_{2}$ end member is known to be very sensitive to the sulfur non stoichiometry "NiS $2-\delta$ ": its unit cell $a$ parameter at room temperature is rather constant, $a=5.688 \AA$, as $\delta$ varies from 0.1 to 0.03 in the sulfur substoichiometric region, but $a$ decreases abruptly for $-0.1 \leq \delta \leq 0$ sulfur excess (corresponding to the formation of $\mathrm{Ni}$ vacancies) to $a \approx 5.677 \AA[6]$. Our measured $a=5.688(1) \AA$ value, consistent with the value $a=5.689 \AA$ reported for the nominal $\mathrm{Ni}_{2}$ sample used for neutron diffraction in ref. [15], strongly suggests that our nominal $\mathrm{NiS}_{2}$ composition leads to a 
sulfur substoichiometric sample as expected from ref. [6]. As x increases, the almost constant value of the a parameter is in good agreement with [6].

The magnetic measurements were performed using either 5T-SQUID magnetometer or ACMS option of a physical properties measurements system (PPMS equipped of a 9 T magnet), both set-ups from Quantum Design. The T-dependent magnetic moment of all the samples was collected within an external applied field of $10^{-2} \mathrm{~T}$, and $1 \mathrm{~T}$ for $\mathrm{x}=0.06$. For $T \leq 300 \mathrm{~K}$, a fourprobe technique in the PPMS was used to measure the electrical resistivity $(\rho)$ as a function of temperature $(T)$. For $T>300 \mathrm{~K}, \rho$ and the Seebeck coefficient $(S)$ were simultaneously recorded within a partial He pressure using an Ulvac Riko ZEM3 system. The low $T(T \leq 300 \mathrm{~K})$ Seebeck coefficient values were measured using a home-made probe (steady state method) inserted in the PPMS. The thermal transport option (TTO) of the PPMS was used to measure the thermal conductivity $(\kappa)$ on the SPS densified bar-shaped samples. For the latter, the surfaces of the obtained pellets were removed to avoid carbon contamination. This allowed also to discard possible sulfur deficient surface layers which could play a role in the transport of pyrites as discussed in the results section. It must be emphasized that the comparison of the resistivity values for the samples before and after SPS densification showed similar values. This allowed to confirm that the role of conducting surface on the apparent transport measurements is much less critical in bulk polycrystalline samples as compared to crystals. Electrical contacts were manually deposited using a silver epoxy on bars of typical 10x2x2mm size. This similar geometry ensured that all $\rho$ changes as a function of $\mathrm{x}(\mathrm{Cu}$ content) correspond to equivalent change in the electrical resistivity. In the first report of surface effects in $\mathrm{NiS}_{2}$ crystals [18], the evidence for it was that the resistance was not 
changing but the resistivity was in crystals of different thicknesses for $\mathrm{T}$ below about $100 \mathrm{~K}$. Thus, the present observed $\rho$ changes for samples of similar geometry at $300 \mathrm{~K}$ would imply that the conducting layers at the surface change with the $\mathrm{Cu}$ content. This means that if the transport is dominated by the surface, the $\mathrm{Cu}$ substitution is also efficient in systematically and reproducibly changing the surface. As seen in the following, as the $\mathrm{Cu}$ content also impacts the thermopower which is less sensitive than $\rho$ (or the Hall effect, not measured) to the surface, and taking into account that the surface removal does not change the resistivity values, we are confident that for $\mathrm{Cu}$ at least the relative change between compounds in the transport properties can be discussed.

\section{3-Results}

3.1- $\mathrm{NiS}_{2}$ : an antiferromagnetic insulator

The $\rho$ value at $300 \mathrm{~K}$ is close to $1.1 \Omega \mathrm{cm}$ for the SPS densified sample (top panel of Fig. 2). This value is very close to the resistivity reported for $\mathrm{NiS}_{2}$ ceramics [6]. More precisely our sample corresponds to the nominal

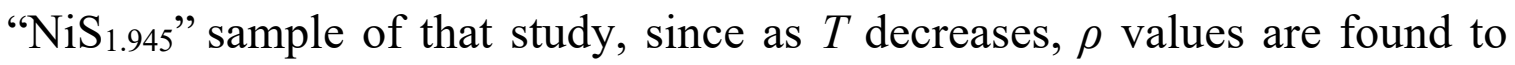
increase to reach values close to $5 \Omega \mathrm{cm}$ at $5 \mathrm{~K}$ in both samples. It must be emphasized that these rather flat curves differ greatly from those reported for crystals showing several orders of magnitude increase as $\mathrm{T}$ decreases even if the $\rho$ value at $300 \mathrm{~K}$ is similar [4]. Also, for our ceramic, the $\rho(\mathrm{T})$ curve shows a change of slope below about $150 \mathrm{~K}$. 
The T-dependent magnetic susceptibility $(\chi)$ curve (middle panel of Fig. 2), shows the appearance of a weak ferromagnetic component associated with the M2 AF phase below $\mathrm{T}_{\mathrm{N} 2}=29.75 \mathrm{~K}$ [15]. The presence of the second transition at $\mathrm{T}_{\mathrm{N} 1}$ can be observed on the inverse of susceptibility $\left(\chi^{-1}(\mathrm{~T})\right.$, same figure), as previously observed in [6]. Furthermore, the lack of Curie-Weiss behavior beyond $40 \mathrm{~K}$ up to $300 \mathrm{~K}$ is consistent with a previous study that showed that this linear regime in the $\chi^{-1}(\mathrm{~T})$ could be reached only above 350 $\mathrm{K}$ [13]. This was shown to come from surviving AF order. At $10 \mathrm{~K}$, consistently with the AF ground state, the weak ferromagnetic component associated to M2 is small (Fig. 3), as attested by the value $M(5 \mathrm{~T})=0.025 \mu_{\mathrm{B}} /$ f.u. from the $M(H)$ curve. Just above $T_{\mathrm{N} 2}(T=30 \mathrm{~K}$ in Fig. 3), i.e. in the $\mathrm{M} 1$ AF phase, this component is suppressed confirming its relation to the M2 AF phase. However, at $T=30 \mathrm{~K}$, the ferromagnetic-like component of M2 is restored by application of a magnetic field as seen in the inset of Fig. 3, where a ferromagnetic component is induced at about $6 \mathrm{~T}$. This indicates some spin flop of the M1 phase. Nevertheless, this weak ferromagnetic component evaluated from the $\chi(T)$ curves is found to differ from study to study. In order to compare our sample to those of others studied by neutron diffraction, one has to quantify the magnetization from the $\mathrm{M}(\mathrm{H})$ curve below $\mathrm{T}_{\mathrm{N} 2}$ as demonstrated by Thio et al [16]. At $10 \mathrm{~K}$, the present $\mathrm{NiS}_{2}$ sample shows a $\mathrm{M}_{0}$ magnetization $\left(\mathrm{M}=\mathrm{M}_{0}+\chi \mathrm{H}\right)$ of $0.016 \mu_{\mathrm{B}} / \mathrm{f}$.u. which is similar to the value for the (111) component in the crystal of ref. [16]. Together with the $\mathrm{T}_{\mathrm{N} 2}$ signature from the $\chi(\mathrm{T})$ curve determined at $29.5 \mathrm{~K}$, these values demonstrate that our sample is representative of $\mathrm{NiS}_{2}$.

As suggested in ref. [15] to explain the thermo-structural study results, Ni could occupy two sites of different charge and magnetic moment in the M2 
phase, indicating a charge disproportionation (or charge ordering). In that respect, the slight tendency to localization at low $\mathrm{T}$ might be related to the M2 phase. However, as changes in the resistivity at low $\mathrm{T}$ were ascribed to surface effects in pyrites [18-20], this correspondence is to be taken with caution.

In contrast, the $S(T)$ curve (Fig. 2, bottom) shows $S \sim 0 \mu \mathrm{V} \cdot \mathrm{K}^{-1}$ values for $\mathrm{T}<100 \mathrm{~K}$ with a $\mathrm{T}$ region where $\mathrm{S}<0$ (inset of bottom panel in Fig. 2). In that low $\mathrm{T}$ region, the groundstate of stoichiometric $\mathrm{NiS}_{2}\left(\mathrm{Ni}^{2+}: \mathrm{t}_{2 \mathrm{~g}}{ }^{6} \mathrm{eg}_{\mathrm{g}}{ }^{2}\right)$ being characteristic of an $e_{g}$ half-filled band system with well splitted $e_{g}$ orbitals, any small deviation from stoichiometry should give either $\mathrm{p}$ - or n-type contribution to $\mathrm{S}$. As shown in ref. [3-5], the $\mathrm{Co}($ or $\mathrm{Cu}$ ) for Ni substitution allows the $e_{g}$ broad band to be less (or more) than half-filled, the transport being thus dominated by electrons (holes). As shown below, our $\mathrm{NiS}_{2}$ sample being slightly less than half-filled, electrons are expected to dominate $\mathrm{S}$ at low $\mathrm{T}$.

$3.2-\mathrm{Ni}_{1-x} \mathrm{Cu}_{x} \mathrm{~S}_{2}$ : inducing the semimetal state by hindering the M2 AF setting

The effect on $\rho$ of the $\mathrm{Cu}$ for Ni substitution in $\mathrm{NiS}_{2}$ is spectacular as $\rho_{300 \mathrm{~K}}$ decreases by about two orders of magnitude for only 7 at. $\% \mathrm{Cu}$ substitution (Fig. 4a). A similar magnitude was reported for single crystals of same compositions in Ref. [3]. Concomitantly, the localized state observed below $\approx 30 \mathrm{~K}$ up to $x=0.04$ is replaced by a metal-like $\mathrm{T}$ dependence for $x \geq$ 0.05 , reaching $\rho_{5 \mathrm{~K}} \approx 4 \mathrm{~m} \Omega \mathrm{cm}$ for $\mathrm{Ni}_{0.93} \mathrm{Cu}_{0.07} \mathrm{~S}_{2}$. Thus, the $\mathrm{Cu}$ substitution induces a change of the "apparent" ground state from insulator $(x=0.00)$ to metal $(x \geq 0.05)$. The resistivity values are consistent with the previous reports [6]. But surface effects might dominate the transport at low T [18-20], and, 
for all the samples corresponding to $x>0.00$, the $\rho(T)$ curves exhibit a broad maximum separating two different conducting regimes, with a maximum at $\sim 110 \mathrm{~K}$ for $x=0.07$, these properties would thus deserve more measurements to be interpreted definitively.

The change of conducting regime below $\mathrm{T}_{\mathrm{N} 2}$ induced by $\mathrm{Cu}$ is apparently connected to the weak ferromagnetic-like component of the M2 AF phase: its signature on the $\chi(T)$ curves is rapidly suppressed as $x$ increases as illustrated in Fig. $4 \mathrm{~b}$ (field cooling process). $\left(\chi_{5 \mathrm{~K}}-\chi_{30 \mathrm{~K}}\right)$ decreases very rapidly from $8.10^{-4} \mathrm{emu}^{-1}$ for $\mathrm{NiS}_{2}$ (main panel) to only $3.10^{-6} \mathrm{emu}^{-1}$ for $\mathrm{Ni}_{0.95} \mathrm{Cu}_{0.05} \mathrm{~S}_{2}$ (inset). This is confirmed also by the $M(H)_{5 \mathrm{~K}}$ curves $(x=0.03$, $x=0.05$ and $x=0.06$ in Fig. 5) which become linear without a hysteretic component for $x=0.05$ and $x=0.06$ showing that the weak ferromagnetic component related to the M2 phase is suppressed.

The $\chi(T)$ curves (inset of Fig. 4b) also reveal a second magnetic transition near $120 \mathrm{~K}$ which could correspond to the systematic maximum on the $\rho(T)$ curves in this $T$ region. This result is consistent with that of Krill et al. [6] obtained also for ceramic samples but prepared by a very different technique. The presence of coupled magnetic and transport transitions in both series of samples makes hardly believable that surface effects dominate the transport in the same manner, as it would imply similar surface states. Thus, cooling the samples from $300 \mathrm{~K}$, it is likely that a small ferromagnetic component sets in first in this high $T$ region, and, for the $x<0.05$ samples, is then followed by a second weak ferromagnetic component below $\mathrm{T}_{\mathrm{N} 2}$ related to the M2 phase. The measurements in a larger magnetic field of $1 \mathrm{~T}$ instead of $10^{-2} \mathrm{~T}$ tend to suppress the $120 \mathrm{~K}$ anomalies which is in favor of this ferromagnetic feature. From these $\chi(T)$ curves, nothing can be said about the M1 AF phase. 
The phase diagram presented in Figure 6 summarizes the main findings. As the $\mathrm{Cu}$ concentration increases, the "apparent" electrical resistivity and the low T magnetic susceptibility simultaneously decrease. From $x=0.02$ to 0.05 , the signature of the magnetic transition at $\mathrm{T}_{\mathrm{N} 2}$ is progressively suppressed. For larger $\mathrm{x}, \mathrm{x}>0.05$, the samples present a metallic behavior at low $\mathrm{T}$ which must have some connection to the disappearance of the AF canting (AFM - M2 phase). The second magnetic transition at $\mathrm{T} \sim 120 \mathrm{~K}$ seems more delicate to interpret though it was also observed in other samples of $\mathrm{Cu}$ substituted $\mathrm{NiS}_{2}$ [6]. This high $\mathrm{T}$ transition might be related to the one observed in [13] in $\mathrm{NiS}_{2}$, where the increase of AFM short range correlations were detected by inelastic neutron scattering below $150 \mathrm{~K}$.

\section{3- Thermopower.}

$\mathrm{NiS}_{2}$ is known to have a $S(T)$ curve with a bell shape as the one shown in figure 7 for the $\mathrm{NiS}_{2}$ SPS ceramic. Below $\approx 100 \mathrm{~K}, S$ values are nearly 0 (see also the $S(T)$ curve in the bottom panel of Fig. 2) and, beyond that temperature, they start to increase reaching positive values as large as $S=$ $+200 \mu \mathrm{V} \cdot \mathrm{K}^{-1}$ at $300 \mathrm{~K}$ and then to decrease as $T$ further increases to reach negative values above $500 \mathrm{~K}$, saturating at $S=-25 \mu \mathrm{V} \cdot \mathrm{K}^{-1}$. A similar behavior for $\mathrm{NiS}_{2}$ was reported in Ref. [4]. According to these authors, at very high $T$, when the $T$-independent entropy term contribution dominates, the negative $S$ values for $\mathrm{NiS}_{2}$ can be assigned to a collapse of the $e_{g}$ bands where electrons dominate due to a possible sulfur non-stoichiometry. Similarly, the maximum $S$ value for $\mathrm{NiS}_{2}$ on the $S(T)$ curve depends on the exact Ni/S stoichiometry [4].

For a stoichiometric sample, the high-T extrapolated $S_{\infty}$ should be exactly $S_{\infty}=0$ as the Ni e gand is half-filled. To explain the value of $S_{\infty}=-25$ 
$\mu \mathrm{V} \cdot \mathrm{K}^{-1}$ at $700 \mathrm{~K}$ (Fig. 7), one can make a comparison with the data reported in ref. [4] for $\mathrm{Ni}_{1-x} \mathrm{Co}_{x} \mathrm{~S}_{2}$. $\mathrm{As} \mathrm{Co}^{2+}\left(d^{7}\right)$ is substituted for $\mathrm{Ni}^{2+}\left(d^{8}\right)$, the $\mathrm{Ni} \mathrm{e}_{\mathrm{g}}$ band becomes less than half-filled and thus $S$ is dominated by electrons from which it results a n-type character. In that respect, the $S_{\infty}<0$ values for our $\mathrm{NiS}_{2}$ indicates a doping similar to that induced by $\mathrm{Co}^{2+}$ as if the $\mathrm{Ni} \mathrm{e}_{\mathrm{g}}$ band is less than half-filled. Indeed, this $S$ value is similar to that of $\mathrm{Ni}_{0.98} \mathrm{Co}_{0.02} \mathrm{~S}_{2}$ [4]. On the opposite, for the $\mathrm{Ni}_{1-x} \mathrm{Cu}_{x} \mathrm{~S}_{2}$ series [3], $d^{9} \mathrm{Cu}^{2+}$ giving electrons to the halffilled $e_{g}$ band, the transport becomes dominated by holes. This explains the sign change of $S$ at high- $T$ experimentally observed in Fig. 7 for the $x=0.01$ and $x=0.07 \mathrm{Ni}_{1-x} \mathrm{Cu}_{x} \mathrm{~S}_{2}$ samples.

As $T$ decreases, the $S$ increase in $\mathrm{NiS}_{2}$ was interpreted [3-5] as the splitting increase of the $\mathrm{e}_{\mathrm{g}}$ band where $S$ becomes dominated by holes in the lower $\mathrm{e}_{\mathrm{g}}$ band. For the present series, as $\mathrm{Cu}$ is substituted for $\mathrm{Ni}$, the bell tends to fall out rapidly and the temperature at which the maximum occurs is pushed higher (Fig. 7). These results are consistent with the previous study [3] showing that the $\mathrm{Cu}$ substitution affects $S$ more rapidly than the Co substitution [4] or than selenium for sulfur substitution [5]. For only 1 at.\% $\mathrm{Cu}$, the $S$ maximum is shifted down to $+90 \mu \mathrm{V} \cdot \mathrm{K}^{-1}$ at $450 \mathrm{~K}$ (instead of a $S$ maximum at $300 \mathrm{~K}$ for the pristine compound) and the negative $T$-independent $S$ values at higher $T$ are no longer observed even at $650 \mathrm{~K}$.

The product $S_{\max } T_{\max }$ is classically used to determine the value of the gap even if corrections should be used when considering narrow gap systems like here [21]. As $\mathrm{Cu}$ content increases, this term decreases, in good agreement with a reduction of the gap. The gap is found to be close to $120 \mathrm{meV}$ for $\mathrm{x}=$ 0 , similar to previous results [22] and decreases to $78 \mathrm{meV}$ for $\mathrm{x}=0.01$, and $11 \mathrm{meV}$ for $\mathrm{x}=0.07$. 
Interestingly, for the $x=0.07$ composition, the $T$ dependence of $S$ at even lower $T$ gives additional information. Below the linear $T$ regime, $S$ shows a shallow upturn in the region below $100 \mathrm{~K}$ with $\mathrm{S}<0$ which could be related to the $T$ region of the $\rho$ maximum observed for several compositions (Fig. 4a). However, this $\mathrm{S}<0$ regime is unexpected as the minerity holes are expected to dominate the Seebeck. For this high $\mathrm{Cu}$ concentration $(\mathrm{x}=0.07)$, it might be that the $\mathrm{Cu}$ orbitals start to participate to the transport, as $\mathrm{CuS}_{2}$ is a metal [17], the description based on the more or less half-filled e $\mathrm{g}_{\mathrm{g}}$ orbital of $\mathrm{Ni}$ becoming erroneous.

From the thermopower data, no obvious relation with the magnetic transition can be deduced. The almost zero values of $\mathrm{S}$ observed for $\mathrm{NiS}_{2}$ suggest a very metallic behavior, and in that respect, the proximity to a metallic state with heavy carriers revealed by pressure [11] could explain these very small thermopower values. Also the perfect combination of two different bands of carriers in a narrow gap semiconductor can explain the $\mathrm{S}(\mathrm{T})$ curve. The $S(T)$ model used in ref. [3-5] to describe $\mathrm{Ni}_{1-x} \mathrm{Co}_{x} \mathrm{~S}_{2}, \mathrm{Ni}_{1-x} \mathrm{Cu}_{x} \mathrm{~S}_{2}$ and $\mathrm{NiS}_{2-x} \mathrm{Se}_{x}$ was based on an $\mathrm{e}_{\mathrm{g}}$ band splitting by the electronic correlations. However, this model failed to reproduce the $S(T)$ properties below $100 \mathrm{~K}$. A new model based on the charge transfer insulator description with two AF transitions and possibly a Ni charge ordering would be worth developing.

\section{4 - Thermal conductivity $(\kappa)$}

As expected from the simple cubic pyrite structure, where the $\mathrm{M}^{2+}$ metallic cation lies in octahedral coordination of S anions, the latter forming $\mathrm{S}_{2}{ }^{2-}$ di-anion sticks, the thermal conductivities of these materials are rather large at $300 \mathrm{~K}$ as illustrated by $\mathrm{FeS}_{2}$ : values of $\kappa \approx 23 \mathrm{~W} \cdot \mathrm{K}^{-1} \mathrm{~m}^{-1}$ and $\kappa \approx 45$ 
$\mathrm{W} \cdot \mathrm{K}^{-1} \cdot \mathrm{m}^{-1}$ were reported for a mineral compound [23] and single crystals [24], respectively. Also, we measured $\kappa$ value of $\sim 11 \mathrm{~W} \cdot \mathrm{K}^{-1} \cdot \mathrm{m}^{-1}$ in a polycrystalline dense $\mathrm{CoS}_{2}$ ceramic [14].

As shown in Fig. 8 for the SPS densified ceramics of $\mathrm{NiS}_{2}$, the value of $\kappa=6.7 \mathrm{~W} \cdot \mathrm{K}^{-1} \cdot \mathrm{m}^{-1}$ at $300 \mathrm{~K}$ is lower than those of $\mathrm{FeS}_{2}$ and $\mathrm{CoS}_{2}$. This might reflect the existence of defects in $\mathrm{NiS}_{2}$ related to its non-stoichiometry invoked to explain the $S<0$ values for $\mathrm{T}>500 \mathrm{~K}$ (Fig. 7). Remarkably, the $\mathrm{Cu}$ for $\mathrm{Ni}$ substitution is very efficient at reducing $\kappa$ (Fig. 8). From $\kappa=6.7 \mathrm{~W} \cdot \mathrm{K}^{-1} \cdot \mathrm{m}^{-1}$ for $\mathrm{NiS}_{2}$, the values at $300 \mathrm{~K}$ decrease rapidly with $\mathrm{x}$ to reach $\kappa=2.5 \mathrm{~W} \cdot \mathrm{K}^{-1} \cdot \mathrm{m}^{-1}$ for $\mathrm{Ni}_{0.93} \mathrm{Cu}_{0.07} \mathrm{~S}_{2}$. Note that $\kappa$ decreases even though $\rho$ decreases by 2 orders of magnitude which is consistent with phonon-dominated $\kappa$. This is confirmed by the calculations of the electronic $\left(\kappa_{e l}\right)$ parts of the total thermal conductivity $(\kappa)$ using the Wiedemann-Franz law and a Lorenz number $\mathrm{L}_{0}=2.45 * 10^{8}$ $\mathrm{W} \Omega \cdot \mathrm{K}^{-2}$. At $300 \mathrm{~K}$, this leads to $\kappa_{e l} / \kappa$ ratios of about $1 / 100$ and $1 / 10$ for $\mathrm{NiS}_{2}$ and $\mathrm{Ni}_{0.93} \mathrm{Cu}_{0.07} \mathrm{~S}_{2}$, respectively.

Considering the small mass difference between $\mathrm{Ni}$ and $\mathrm{Cu}$, and the small level $(7 \%)$ of substitution, the origin of this $\kappa$ reduction by a factor of 2.5 at $300 \mathrm{~K}$ cannot be simply ascribed to the alloying effect. This is supported by recent $\kappa$ data reported for the $\mathrm{Co}_{1-\mathrm{x}} \mathrm{Fe}_{\mathrm{x}} \mathrm{S}_{2}$ pyrite series $(\mathrm{x} \leq 0.3)$ showing that the lattice part ( $\kappa_{\text {latt }}$ ) of the thermal conductivity is unchanged even for $30 \%$ substitution [25]. In that respect, the lack of $\kappa$ data for $\mathrm{CuS}_{2}$ makes difficult the extraction of the important parameters governing the thermal conductivity in the pyrite series. As $\mathrm{FeS}_{2}$ is a diamagnetic semiconductor but exhibits a large RT $\kappa$, much larger than the value reported for $\mathrm{CoS}_{2}$ which is an itinerant ferromagnet, it seems that there exists no direct relation between $\rho$ and $\kappa$, the latter being driven principally by phonons. 
As $\mathrm{T}$ decreases below $\mathrm{T}_{\mathrm{N} 2}$, the thermal conductivity strongly increases showing that the AFM alignment favors the phonon propagation in $\mathrm{NiS}_{2}$. This leads to a peak in $\kappa$ at $\sim 12 \mathrm{~K}$, which can not be related to a classical peak at $\sim$ $\theta_{\mathrm{D}} / 5$, as $\theta_{\mathrm{D}}=445 \mathrm{~K}$ in $\mathrm{NiS}_{2}$ [26]. As $\mathrm{x}$ increases, this upturn disappears. The same effect was previously observed in the pyrites $\mathrm{Co}_{1-\mathrm{x}} \mathrm{Fe}_{\mathrm{x}} \mathrm{S}_{2}$ as $\mathrm{x}$ increases [25] and is commonly observed in other materials such as filled skutterudites [27]. The impact of $\mathrm{Cu}$ substitution is thus very efficient to reduce the thermal conductivity also in the magnetically ordered state of these pyrites.

\section{4 - Discussions and concluding remarks}

For thermoelectric properties, the bell shape $S(T)$ curve of $\mathrm{NiS}_{2}$ is interesting as $S$ exhibits very large values at the top of the dome though counterbalanced by a too low electrical conductivity. The latter can be drastically increased by $\mathrm{Cu}^{2+}$ for $\mathrm{Ni}^{2+}$ doping as shown by the present results with room temperature $\rho$ values decreasing from few $\Omega \cdot \mathrm{cm}$ to few $\mathrm{m} \Omega \mathrm{cm}$. Concomitantly, the $S$ maximum values rapidly decrease as $x$ increases in $\mathrm{Ni}_{1}$ ${ }_{x} \mathrm{Cu}_{x} \mathrm{~S}_{2}$, the $T$ at the maximum shifting from $300 \mathrm{~K}$ for $\mathrm{NiS}_{2}$ to $450 \mathrm{~K}$ for $\mathrm{Ni}_{0.99} \mathrm{Cu}_{0.01} \mathrm{~S}_{2}$. As the high positive $S$ value of the pristine compound is related to near perfect half filling of the e orbitals of $3 d^{8} \mathrm{Ni}^{2+}$, the substitution by $\mathrm{Cu}^{2+}$ creates a conduction dominated by holes. In the high $T$, this is confirmed by $S$ $>0$ values contrasting with the $S<0$ and $T$-independent values observed for the $\mathrm{Ni}_{1-x} \mathrm{Co}_{x} \mathrm{~S}_{2}$ samples, i.e. when the e $\mathrm{g}_{\mathrm{g}}$ band is less than half-filled.

The $S(T)$ curves for $T \leq 300 \mathrm{~K}$ confirm that, for $x>0.00$, a metalliclike regime is at play over a broad T range with $S \sim T$, despite that the $\rho(T)$ curves exhibit a $(\mathrm{d} \rho / \mathrm{d} T)<0$ slope from $T>\sim 120 \mathrm{~K}$. Nevertheless, since the $T$ 
dependence is very small, as for $\mathrm{Ni}_{0.93} \mathrm{Cu}_{0.07} \mathrm{~S}_{2} \rho$ decreasing only from 4 $\mathrm{m} \Omega \mathrm{cm}$ at $300 \mathrm{~K}$ to $3 \mathrm{~m} \Omega \mathrm{cm}$ at $650 \mathrm{~K}$, these materials can be classified as semimetals.

The third physical quantity to be considered for thermoelectricity is the thermal conductivity. Our measurements performed on selected dense ceramics are consistent with phonons dominated $\kappa$ with rather large values. However, the $\mathrm{NiS}_{2} \kappa$ value is lower than those of other $\mathrm{FeS}_{2}$ and $\mathrm{CoS}_{2}$ pyrites $[23-24,14], \kappa$ decreasing as the number of $d$ electrons increases. Moreover, the $\mathrm{Cu}$ substitution for $\mathrm{Ni}$ is very efficient to reduce $\kappa, 7$ at. $\% \mathrm{Cu}$ for $\mathrm{Ni}$ inducing a reduction by a factor of 2.5 at $300 \mathrm{~K}$. This effect, much greater than that of Fe-substituted $\mathrm{CoS}_{2}$ [25], supports the peculiar role of $\mathrm{Cu}$ in sulfides as compared to $\mathrm{Fe}, \mathrm{Co}$ or $\mathrm{Ni}$. The $\mathrm{Cu}$ efficiency in reducing $\kappa$ might be related to the fact that $\mathrm{CuS}_{2}$ does not form in normal conditions but requires high pressure [27]. In that respect, as $\mathrm{Cu}$ in binary sulfides, such as $\mathrm{Cu}_{2} \mathrm{~S}$ and $\mathrm{CuS}$, adopts coordination other than octahedral, its substitution at $\mathrm{NiS}_{6}$ octahedral sites might be energetically unfavorable. This would imply that the atomic structure near $\mathrm{Cu}$ might not remain cubic pyrite, creating local structural distortions responsible for this strong impact on the lattice part of $\kappa$.

While the combination of these physical quantities $(\rho, S, \kappa)$ leads to very low thermoelectric figures of merit, the low $T$ measurements still give interesting insights in the complex physics of these materials. The insulating AF M2 ground state of $\mathrm{NiS}_{2}$ is rapidly replaced by a metallic AF state M1 when $x \geq$ 0.05 in $\mathrm{Ni}_{1-x} \mathrm{Cu}_{x} \mathrm{~S}_{2}$. Thus, this substitution induces an insulator to metal transition. Concomitantly, the signature of the $\mathrm{AF}$ transition at $T_{\mathrm{N} 2} \approx 30 \mathrm{~K}$ is progressively suppressed as $x$ increases which demonstrates that the insulating low $T$ state is related to this AF phase. The isothermal $M(H)_{T=5 \mathrm{~K}}$ curves also 
support this trend. In addition to these coupled electrical and magnetic transitions, there exists for $\mathrm{NiS}_{2}$ a clear change in the thermal conductivity below $\mathrm{T}_{\mathrm{N} 2}$ suggesting a spin/charge/phonon coupling for this $T$ region. Alternatively, the existence of a Ni charge ordering would be also consistent with the present observations. Additional measurements at low $T$ are now necessary to confirm the hypothesis of Ni disproportionation.

\section{Acknowledgments}

This work is supported by the French Agence Nationale de le Recherche (ANR) through the Labex program EMC3 (ANR-10-LABX-09-01) and the COVATIS project. 


\section{References:}

1. T. Fujii, K. Tanaka, F. Marumo and Y. Noda, Mineralogical Journal 13, 448 (1987).

2. J. M. Baker, R. J. Birgeneau, M. T. Hutchings and J. D. Riley, Phys. Rev. Lett. 21, 620 (1968).

3. P. Kwizera, A.K. Mabatah, M.S. Dresselhaus and D. Adler, Phys. Rev. B 24, 2972 (1981).

4. A.K. Mabatah, E.Y. Yoffa, P.C. Eklund, M.S. Dresselhaus and D. Adler, Phys. Rev. B 21, 1676 (1980).

5. P. Kwizera, M.S. Dresselhaus and D. Adler, Phys. Rev. B 21, 2328 (1980).

6. G. Krill, M.F. Lapierre, F. Gautier, C. Robert, G. Czjzek, J. Fink and H. Schmidt, J.Phys. C: Solid State Phys. 9, 761 (1976).

7. H.C. Xu, Y. Zhang, M. Xu, R. Peng, X.P. Shen, V.N. Strocov, M. Shi, M. Kobayashi, T. Schmitt, B.P. Xie and D.L. Feng, Phys. Rev. Lett. 112, 087603 (2014).

8. C. Schuster, M. Gatti and A. Rubio, Eur. Phys. J B 85, 325 (2012).

9. A. Fujimori, K. Mamiya, T. Mizokawa, T. Miyadai, T. Sekiguchi, H. Takahashi, N. Mori and S. Suga, Phys. Rev. B 54, 16329 (1996).

10. A. Perucchi, C. Marini, M. Valentini, P. Postorino, R. Sopracase, P. Dore, P. Hansmann, O. Jepsen, G. Sangiovanni, A. Toschi, K. Held, D. Topwal, D. D. Sarma and S. Lupi, Phys. Rev. B 80, 073101 (2009).

11. S. Friedemann, H. Chang, M. B. Gamża, P. Reiss, X. Chen, P. Alireza, W. A. Coniglio, D. Graf, S. Tozer, F. M. Grosche, Sci. Reports 6, 25325 (2016).

12. H. Takano and A. Okiji, J. Phys. Soc. Jpn 51, 1128 (1982). 
13. M. Matsuura, Y. Endoh, H. Hiraka, K. Yamada, A. S. Mishchenko, N. Nagaosa, and I. V. Solovyev, Phys. Rev. B68, 094409 (2003).

14. S. Hébert, E. Guilmeau, D. Berthebaud, O.I. Lebedev, V. Roddatis and A. Maignan, J. Appl. Phys. 114, 103703 (2013).

15. S. Yano, D. Lonca, J. Yang, U. Chatterjee, D.E. Bugaris, D.Y. Chung, L. Peng, M. Graysor and M.G. Kanatzidis, Phys. Rev. B 93, 024409 (2016).

16. T. Thio, J.W. Bennett and T.R. Thurston, Phys. Rev. B 52, 3555 (1995).

17. H. Ueda, M. Nohara, K. Kitazawa, H. Takagi, A. Fujimori, T. Mizokawa and T. Yagi, Phys. Rev. B 65, 155104 (2002).

18. T. Thio and J. W. Bennett, Phys. Rev. B 50, 10574 (1994).

19. M. Limpinsel, N. Farhi, N. Berry, J. Lindemuth, C. L. Perkins, Q. Linf and M. Law, Environ. Sci. 7, 1974 (2014).

20. J. Walter, X. Zhang, B. Voigt, R. Hool, M. Manno, F. Mork, E. S. Aydil and C. Leighton, Phys. Rev. Mater. 1, 065403 (2017).

21. Z. M. Gibbs, H- S. Kim, H. Wang, G. J. Snyder, Appl. Phys. Lett. 106, $022112(2015)$.

22. T.A. Bither, C.T. Prewitt, J.L. Gillson, P.E. Bierstedt, R.B. Flippen and H.S.Young, Solid State Comm. 4, 533 (1966).

23. C. Clauser and E. Huenges, "Thermal Conductivity of Rocks and Minerals", p. 121, in Rock Physics \& Phase Relations: A Handbook of Physical Constants, Ed.: Thomas J. Ahrens, Wiley, 2013, DOI: 10.1029/RF003.

24. P. A. Popov, P. P. Fedorov, and S. V. Kuznetsov, Crystallography Reports, $58,319(2013)$. 
25. U. Acevedo Salas, I. Fourati, J. Juraszek, F. Richomme, D. Pelloquin, A. Maignan, S. Hébert, Phil. Trans. A, Phil. Trans. R. Soc. A 377: 20180337 (2019).

26. S. Ogawa, Jpn J. Phys. Soc. 41, 462 (1976).

27. G. S. Nolas, J. Yang, H. J. Goldsmid, in 'Thermal conductivity, Theory, Properties and Applications', Edited by Terry Tritt, Editor Kluwer Academic / Plenum Publishers (2004). 


\section{Figure captions:}

Fig. 1: Powder $\mathrm{X}$-ray diffraction patterns of the $\mathrm{Ni}_{1-\mathrm{x}} \mathrm{Cu}_{\mathrm{x}} \mathrm{S}_{2}$ samples $(\mathrm{x}=0.00$, $\mathrm{x}=0.01$ and $\mathrm{x}=0.07)$.

Fig. 2: $\mathrm{NiS}_{2}$ : T dependence (below $300 \mathrm{~K}$ ) of $\rho$ (top; inset : the $\ln (\rho)$ data as a function of $1 / \mathrm{T}$ ), $\chi$ (field-cooling mode, $10^{-2} \mathrm{~T}$, middle, ( $\square$ )) and $\mathrm{S}$ (bottom). The reciprocal magnetic susceptibility is also given in the middle panel (०). An enlargement of $\mathrm{S}$ at low $\mathrm{T}$ is given as an inset in the bottom panel.

Fig. 3: $\mathrm{NiS}_{2}$ : isothermal $\mathrm{H}$ dependence of the magnetization $\mathrm{M}$ collected up to 5T. Inset: $\mathrm{M}(\mathrm{H})_{\mathrm{T}=30 \mathrm{~K}}$ curve up to $9 \mathrm{~T}$.

Fig. 4: $\mathrm{Ni}_{1-\mathrm{x}} \mathrm{Cu}_{\mathrm{x}} \mathrm{S}_{2}$ : (a) $\rho(\mathrm{T})$ and (b) $\chi(\mathrm{T})$ registered in field-cooling mode $\left(10^{-}\right.$ $\left.{ }^{2} \mathrm{~T}\right) . \mathrm{x}$ values are labelled in the graphs.

Fig. 5: $\mathrm{Ni}_{1-\mathrm{x}} \mathrm{Cu}_{\mathrm{x}} \mathrm{S}_{2}: \mathrm{M}(\mathrm{H})_{5 \mathrm{~K}} . \mathrm{x}$ values are labelled in the graphs.

Fig.6 : Phase diagram of $\mathrm{Ni}_{1-\mathrm{x}} \mathrm{Cu}_{\mathrm{x}} \mathrm{S}_{2}$ presenting as a function of $\mathrm{x}$ the values of $\rho$ at $5 \mathrm{~K}$ and of $\chi$ (left-scale), and the values of the magnetic transitions $\mathrm{T}_{\mathrm{N} 2}$ and $\mathrm{T}_{\text {onset }}$ (right scale) extracted from the $\chi(\mathrm{T})$ curves in Fig. $4 \mathrm{~b}$.

Fig. 7: $\mathrm{S}(\mathrm{T})$ curves of the SPS densified $\mathrm{Ni}_{1-\mathrm{x}} \mathrm{Cu}_{\mathrm{x}} \mathrm{S}_{2}$ samples $(\mathrm{x}=0.00, \mathrm{x}=0.01$ and $\mathrm{x}=0.07$ ) as a function of $\mathrm{T}$. $\mathrm{x}$ values are labelled in the graph.

Fig. 8: $\kappa(\mathrm{T})$ curves of the SPS densified $\mathrm{Ni}_{1-\mathrm{x}} \mathrm{Cu}_{\mathrm{x}} \mathrm{S}_{2}$ samples $(\mathrm{x}=0.00, \mathrm{x}=0.01$ and $\mathrm{x}=0.07)$. $\mathrm{x}$ values are labelled in the graphs. 
Figure 1 
Figure 2

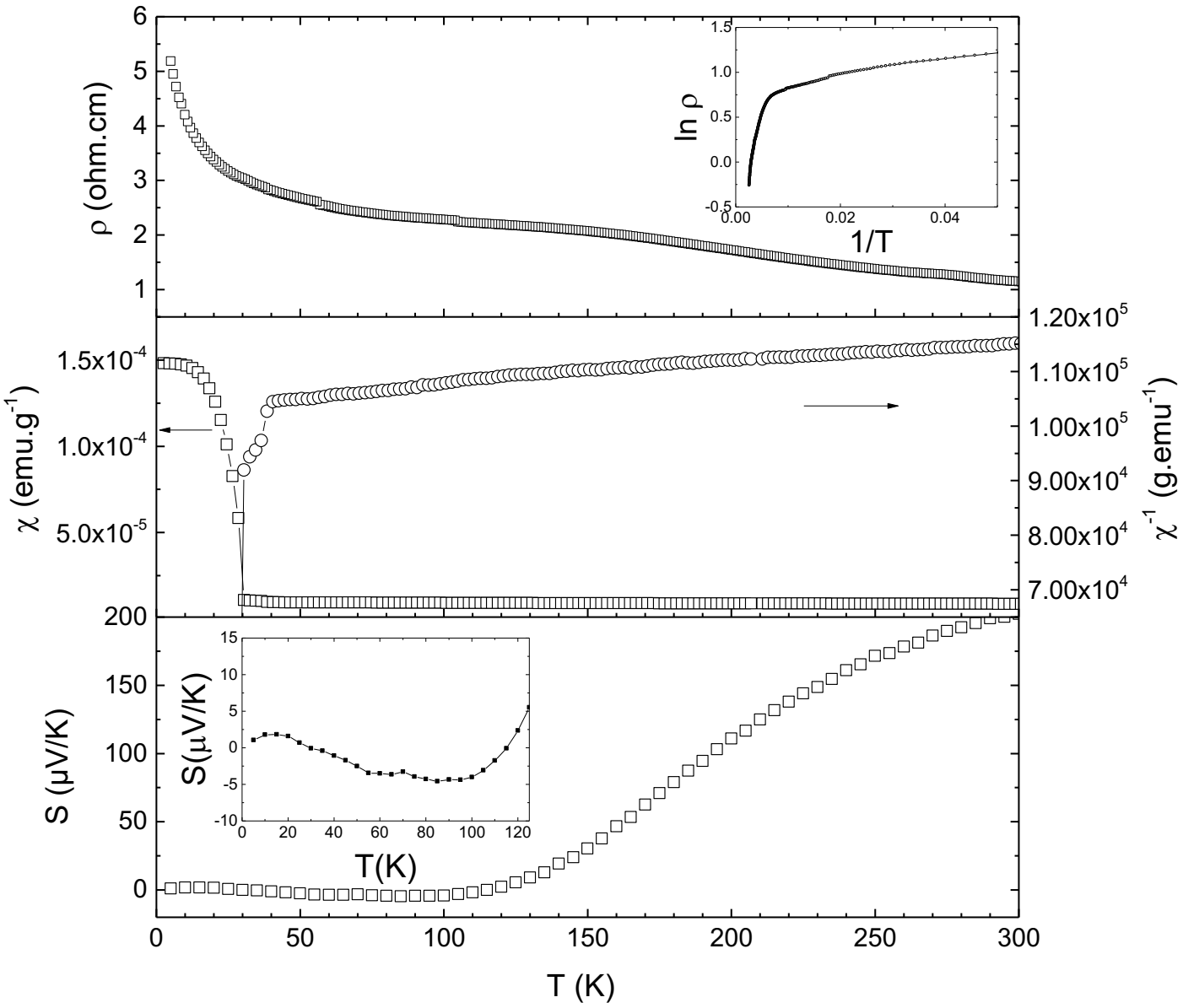


Figure 3

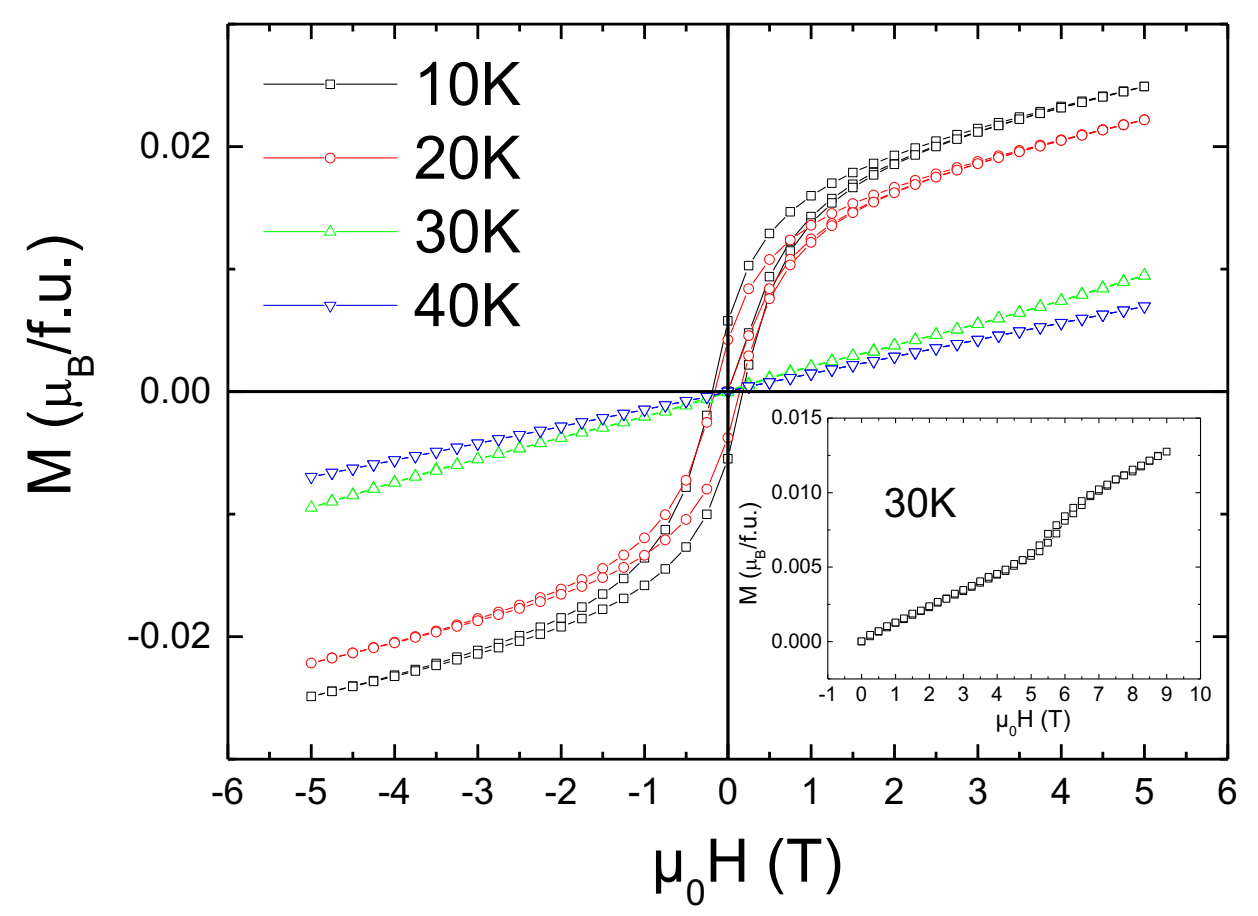


Figure 4a

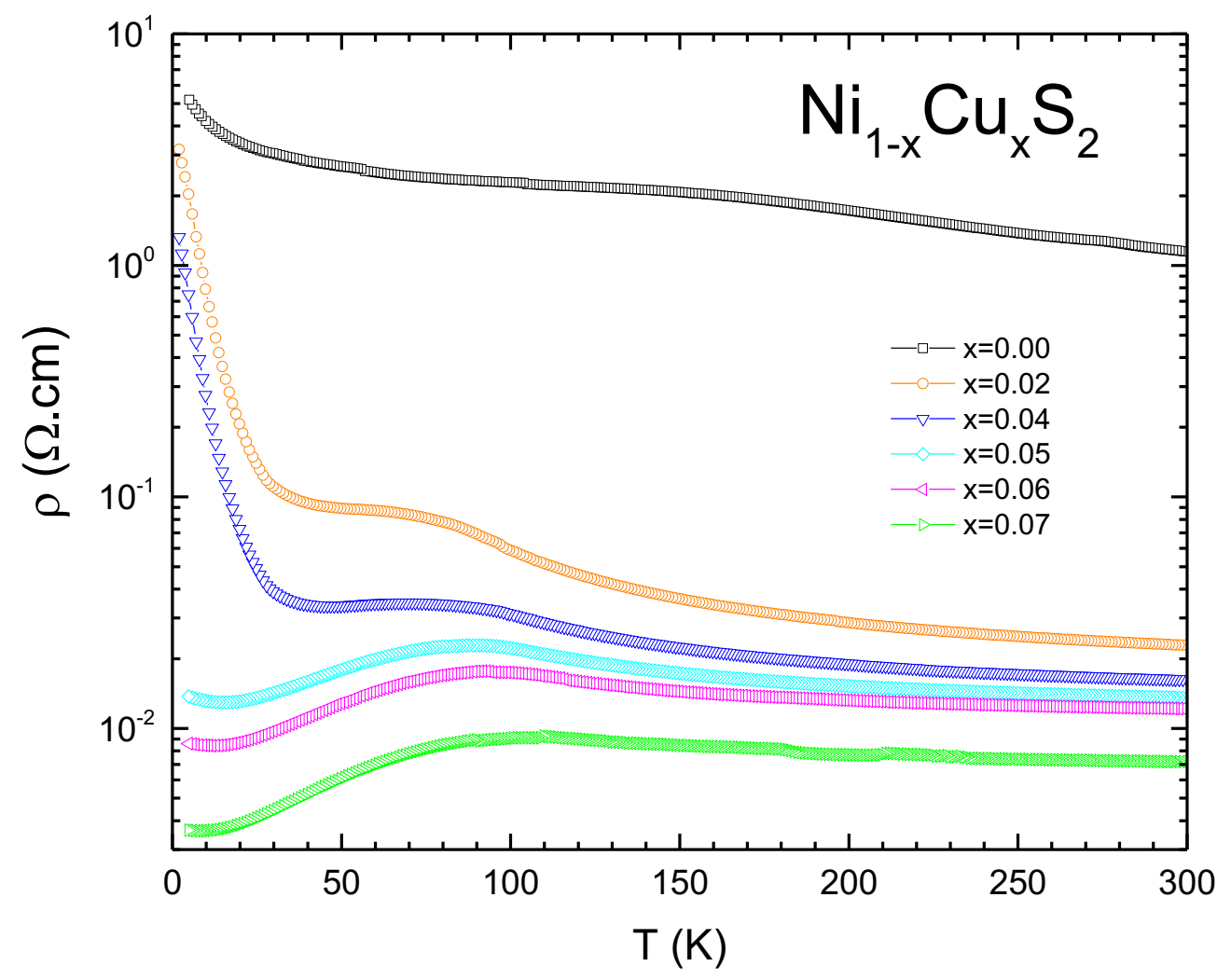


Figure 4b

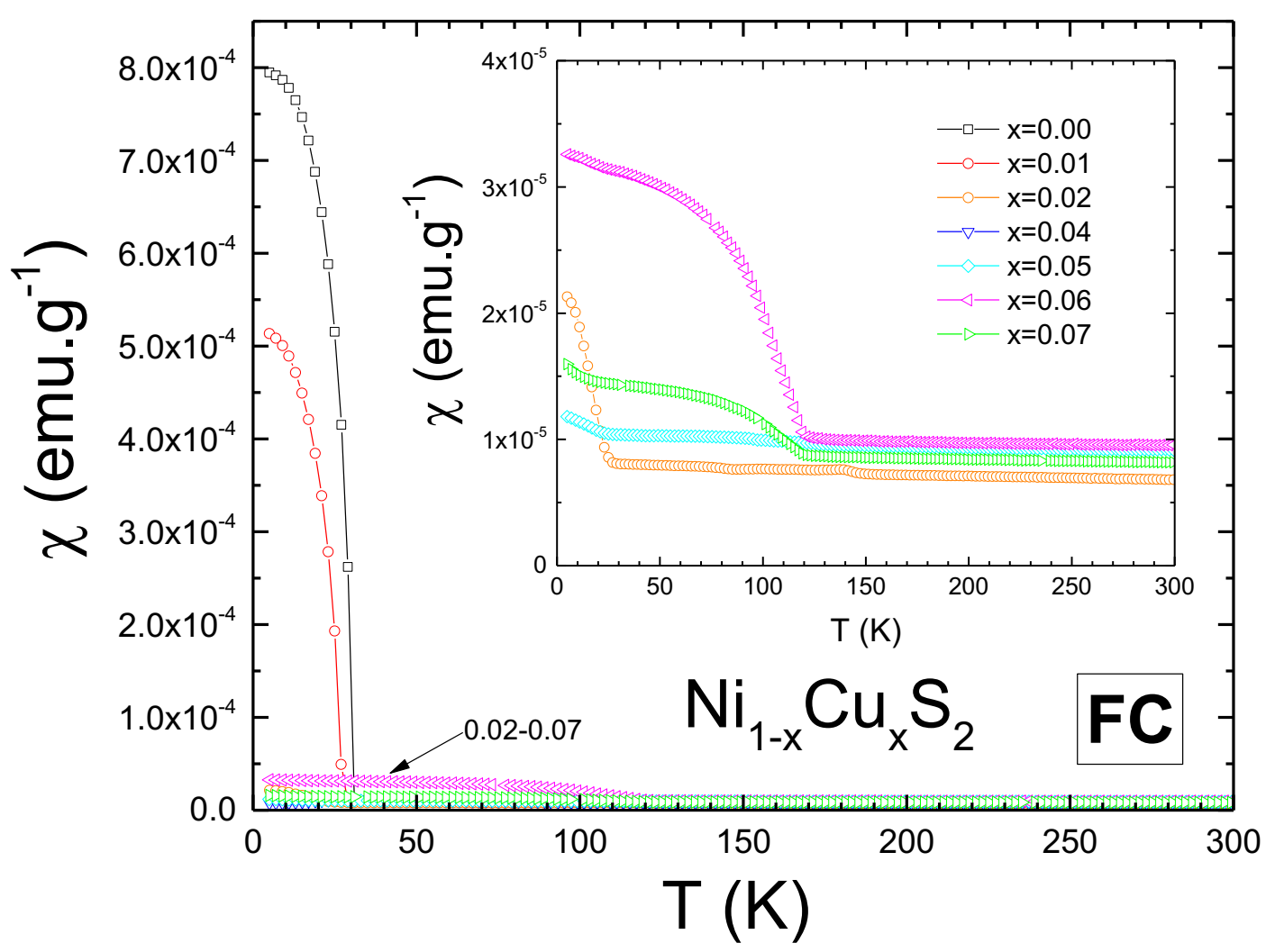


Figure 5

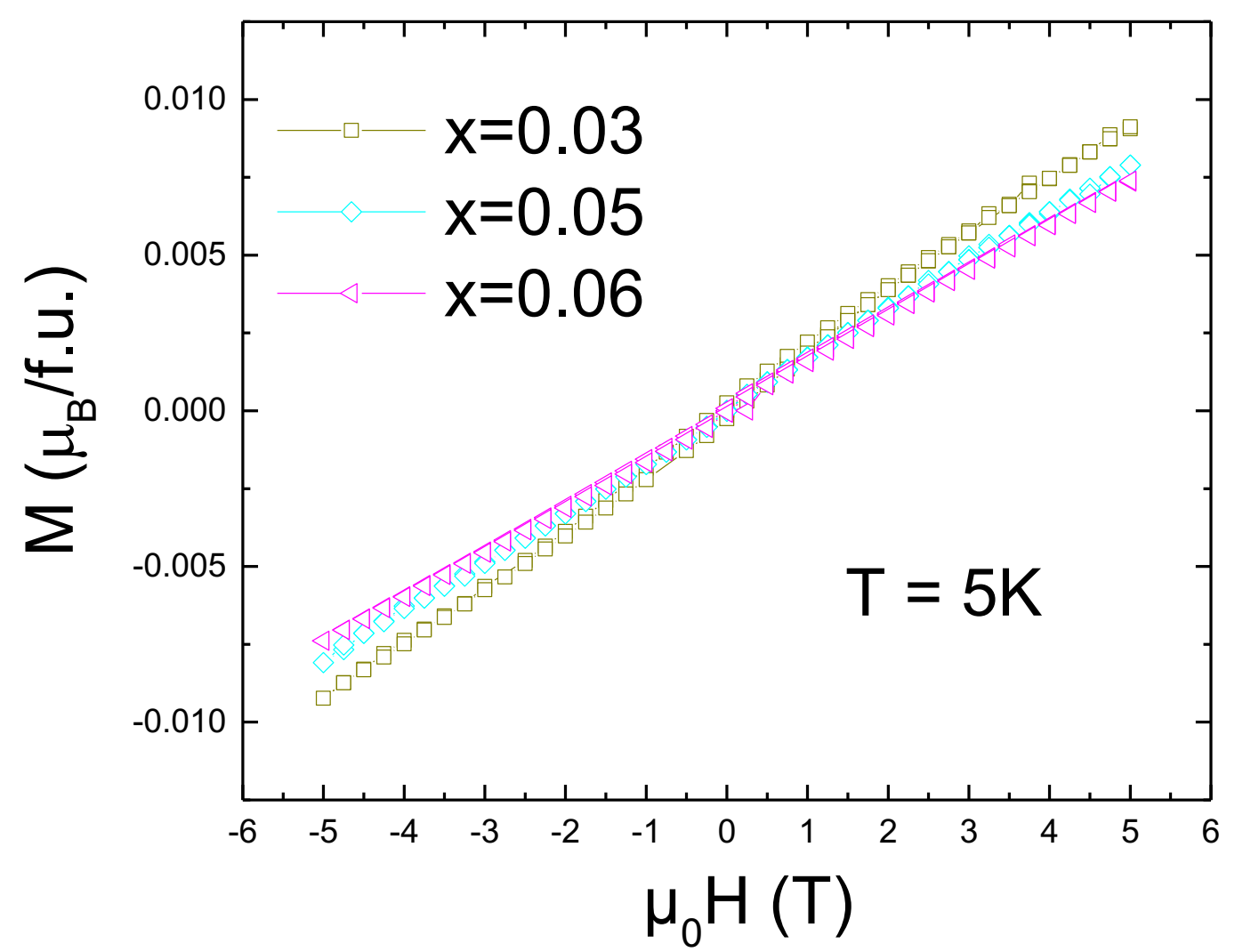




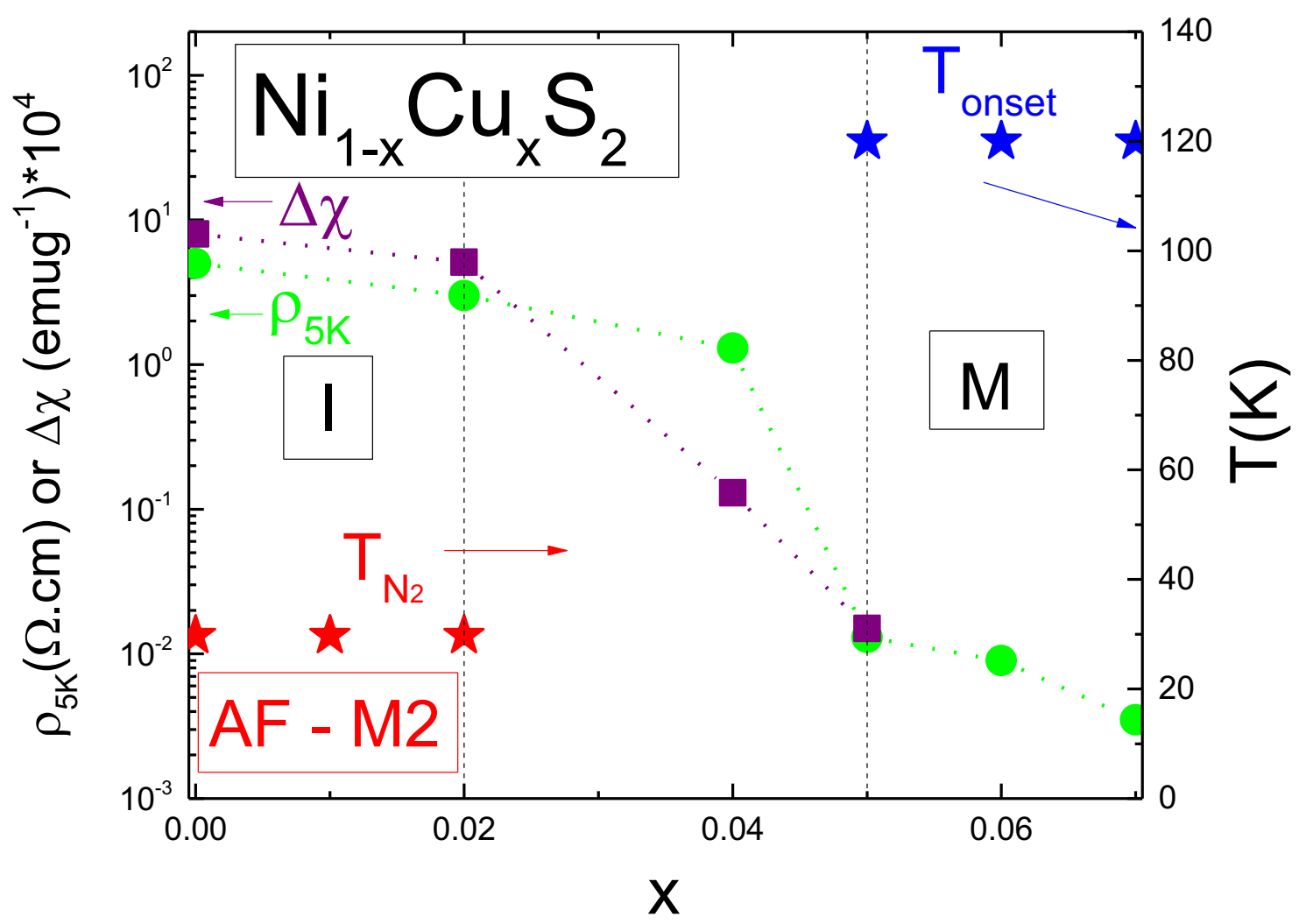

Figure 6 
Figure 7

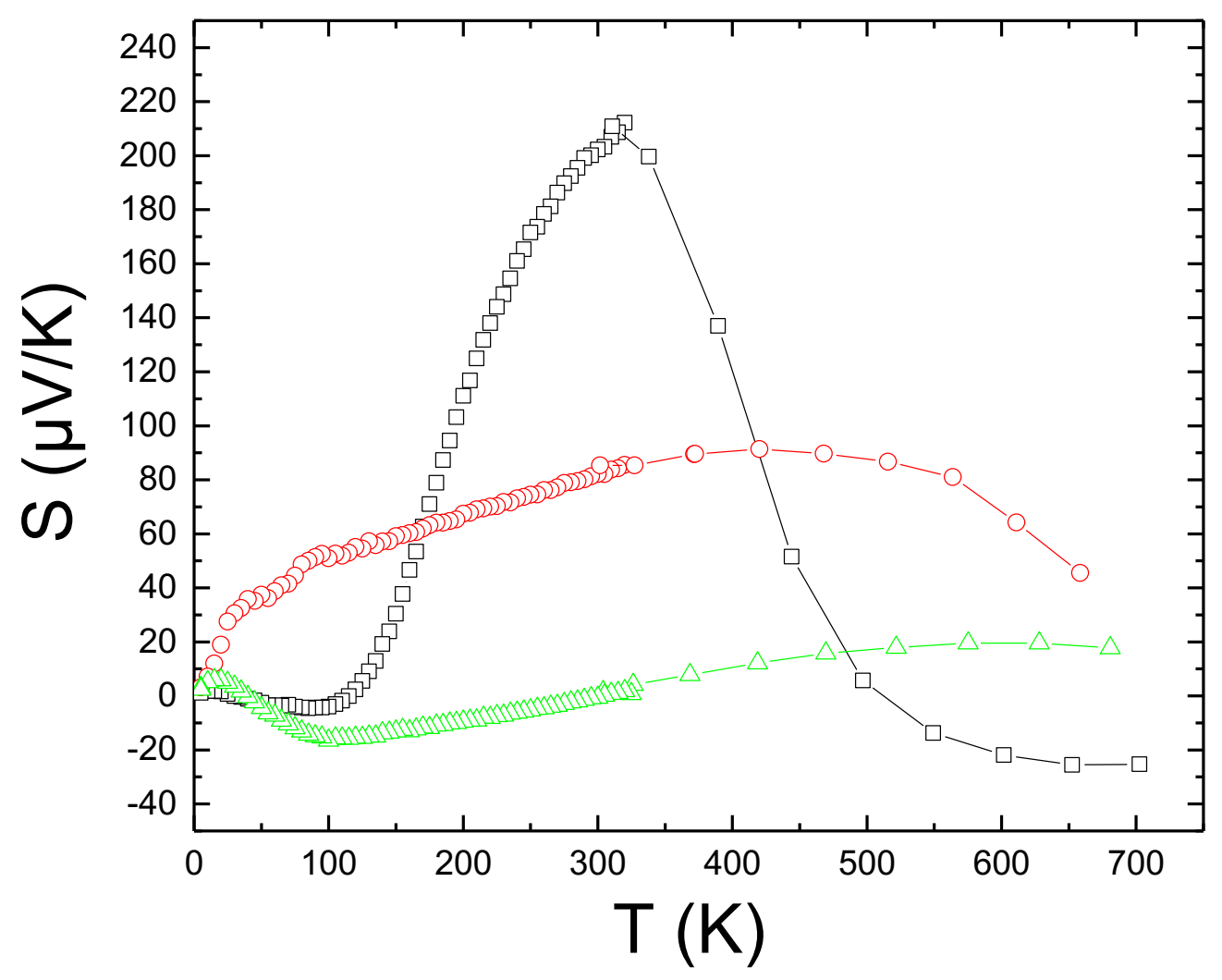


Figure 8

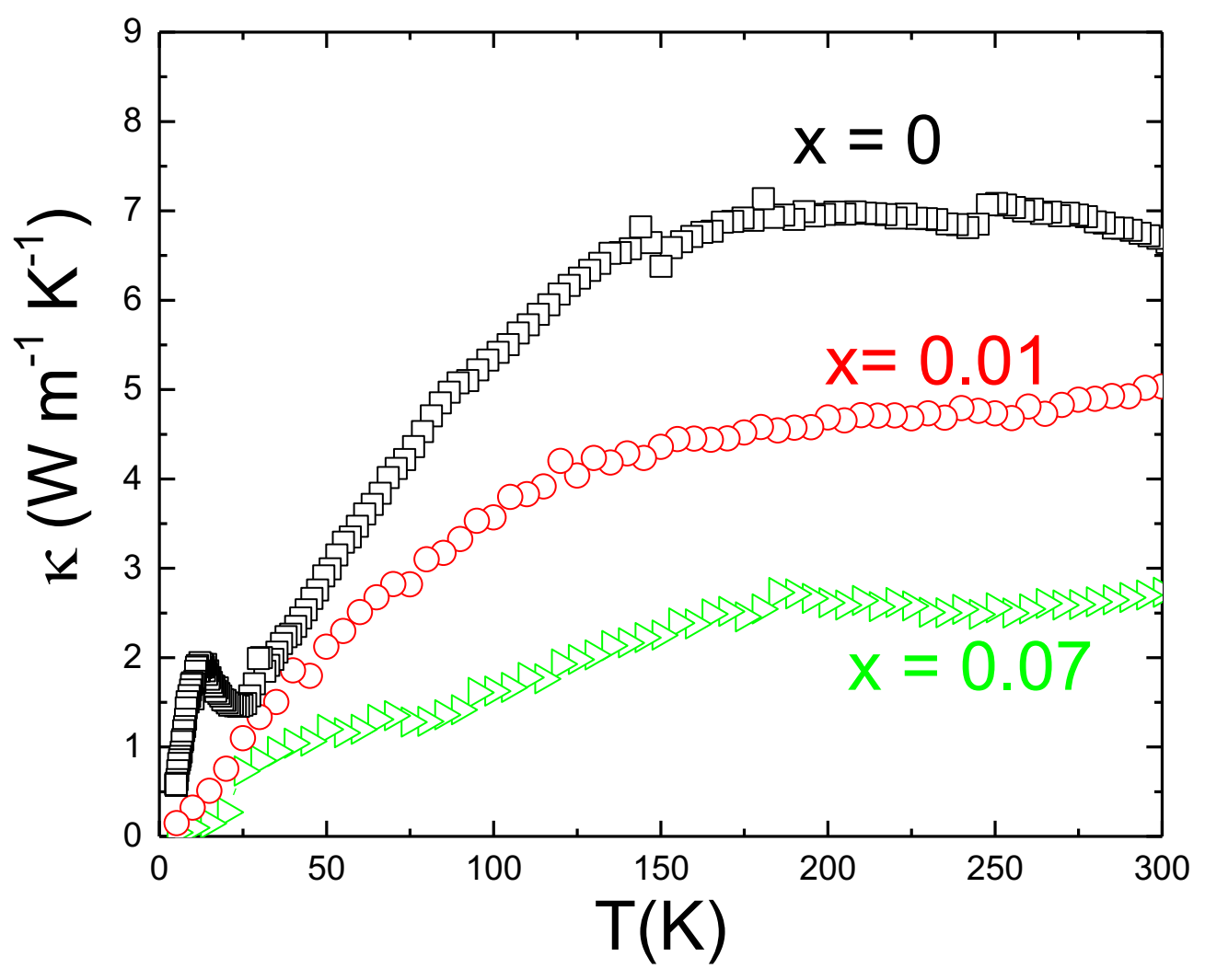

